\title{
LA CONSTRUCCIÓN DEL TRABAJO SOCIAL CONTEMPORÁNEO*
}

Teresa Matus 


\section{RESUMEN}

La profesora Matus nos invita a reflexionar acerca de cómo pensar los cambios?, a partir de esta premisa, Cómo podemos preguntarnos que tipo de intervención social se está gestando? Qué tipo de ámbito público en nuestros países? Cómo vivenciarlo? Pues su hipótesis central es que las formas de intervención social no son sólo operacionales, a través de ellas se configura lo público; el espacio de aparición de lo público, no pre-existe a la acción sino que existe y se desvanece con su ausencia, es decir, dependiendo del tipo de intervención social que hagamos, la dinámica de la realidad social va a contener distintas formas de expresión.

a premisa central del trabajo que yo quiero presentar para ustedes, es describir algunas hipótesis en términos de paradoja, en términos de contradicciones sociales presentes en la sociedad latinoamericana, que constituyen entonces una serie de escenarios de plataforma, de desafíos de proyección para el trabajo social presente.

La ponencia la he devidido en tres partes:

La primera tiene que ver con la intervención social en lo que Hana Arentd llama: Bajo resplandor de lo público, y aquí la idea central es que la tarea de intervención social es considerada como una operacionalización en términos de políticas sociales y la hipótesis que quiero compartir es que las formas de intervención social no son sólo operacionales, a través de ellas se configura lo público; el espacio de aparición de lo público, no preexiste a la acción sino que existe y se desvanece con su ausencia, es decir, depende del tipo de intervención social que hagamos, la dinámica dela realidad social va a contener distintas maneras de expresión.

De allí que de alguna forma lo más interesante en lo que nosotros podemos dar cuenta, tiene que ver, fundamentalmente con ¿cómo pensar los cambios en la integración social?, a partir de esta premisa, preguntarnos ¿qué tipo de integración se está gestando?, ¿qué tipo de ámbito público en nuestros países?, ¿cómo poder armar esto y vivenciarlo?

* Este artículo corresponde a la ponencia de la chilena Teresa Matus, preparada para el XI Congreso de Trabajo Social, Manizales 19-22 de Agosto de 2003. Dicha charla (video-conferencia) fue transcrita por Maria Carolina Tabares B. para la Revista Prospectiva N $^{\circ} 8$. 
Aprovechando que este año se celebra 100 años del nacimiento de Teodoro Adorno, la propuesta es justamente avanzar por negatividad, es decir, muchas veces nosotros no sabemos cambiar de una dimensión teórica a otra, o de una innovación práctica a otra, pero sí sabemos cómo ya no queremos hacer las cosas; en este sentido avanzar por negatividad, es reconocer, es presentar ciertos nudos, ciertas contradicciones, que de alguna manera se nos presentan como un antecedente, como un diagnóstico y como un desafío para enfrentar la intervención social en este congreso. Así entonces el primero de ellos, la primera contradicción que a mí me parece interesante compartir con ustedes es la siguiente: en América Latina nos hemos constituido como un caso anti-ejemplar, porque si bien es cierto en la última década hubo un crecimiento en términos de crecimiento económico, ese éxito ha sido desventurado porque lo hemos conseguido al precio de intensificar, de aumentar como nunca antes la brecha entre ricos y pobres, por lo tanto tenemos a la vez, crecimiento económico con desigualdad social, esto por lo menos echa por tierra esa cierta idea de una lógica de un modo en que la personas no optaron por tener o alimentar unas políticas de mayor crecimiento económico o se trazaron en términos de distribución social.

Por lo tanto, el primer nudo que enfrentamos en la intervención social es que ya es una ilusión optar por esos modelos. Muy bien, lo sabemos nosotros los chilenos con más de 20 años de neoliberalismo, la idea de que si crecíamos todos, todos íbamos a mejorar en su conjunto es una falacia, como se demuestra hoy en los estudios de inequidad que se por ejemplo han hecho Blitehuz en América Latina, en los que muestra que justamente la desigualdad social no solo se vuelve persistente sino que esa desigualdad social de alguna forma está impidiendo la posibilidad de un mejor estándar, de un mejor nivel de vida, que abarque no solo a las clases acomodadas de la población latinoamericana sino que también genere un sistema de protección social en las clases más desprotegidas del continente.

Entonces, en ese sentido, como va a decir el secretario de la OEA, resulta paradójico que un hemisferio tan rico en posibilidades y recursos haya dejado a millones de sus hijos desamparados, atrapados en las garras de la miseria. Por lo tanto, nosotros hoy tenemos un tipo de crecimiento económico, pero de un modelo que enfatiza cada vez más un sistema de desprotección social, y esta es la segunda hipótesis que yo quería compartir, como a mi me gusta llamarlo, "nosotros nos hemos quedado a solas con Dios", porque en la dinámica de la dialéctica del iluminismo cuando Adorno y Horheimer nos hacían ver que la divinidad podía vencer el temor entre los sujetos, lo importante allí es vencer a los dioses, porque el vencimiento de los dioses constituía la posibilidad del vencimiento del temor; sin embargo, para eso se hizo una apuesta a la racionalidad instrumental y sobre todo a los mecanismos de los presupuestos en términos del mercado. Estos mecanismos en vez de asegurar mayores niveles de protección, nos han sumido hoy día por niveles de responsabilidad individual, en sistemas mayores de desprotección social, eso significa 
que es el individuo el que tiene que "asegurarse", por lo tanto la contradicción es evidente, la responsabilidad social se encuentra ausente porque el sistema opera con relativa autonomía del individuo y asume los criterios de rentabilidad empresarial; por lo tanto, la seguridad social se transforma, incluso, en un producto de mercado a ser comprado por los individuos, de ahí que el Estado sea nuevamente requerido para, en cierto modo, hacerse cargo de aquellos usuarios que se han vuelto "incompetentes" para poder buscar por sí mismos mecanismos de protección.

Fíjense ustedes las reformas previsionales de educación, de salud y de seguridad social, realizadas en el 78, nos entregan ya un tiempo largo y un sitio largo como para poder evaluar y lo que realmente ha pasado es que los sistemas privados se han hecho cargo de aquellos usuarios más lucrativos y que podían pagar, pero, los desposeídos se han dado una larga vuelta para volver al Estado, pero el Estado de hoy no es el mismo Estado que por lo menos tenía la expectativa, el sueño, la promesa de volverse en un Estado de Bienestar; el Estado de Bienestar no solo está en decadencia práctica sino, lo más importante, en decadencia conceptual. Se nos dice a todos los latinoamericanos que ya ni si quiera podemos optar por la idea de tener un Estado Social de Bienestar; esto no es dar protección a los sujetos, sino verdaderamente al capital.

Hoy día, recordando al mismo Marx, uno podría decir que aunque se habla de capital humano, de capital social, de aumentar la asociatividad entre las personas, no podemos perder de vista que eso sigue estando en la lógica exhaustiva y exigente del capital, entonces en este caso, el capital a través de todos los sistemas que buscan la producción social, está protegido por dos razones fundamentales, la primera, es porque de la pobreza y de los sectores más desposeídos hay una lección para que el Estado se encargue, o los mecanismos fortalecidos de la sociedad civil, y en segundo lugar, están protegidos de las dificultades de los riegos bursátiles de los usuarios que participan en el sistema, porque aquí somos nosotros mismos los que de alguna manera tendremos que hacernos responsables. Entonces, estas dos hipótesis, América Latina a la vez está hoy con tasas de crecimiento económico y enormes desigualdades sociales, un sistema neoliberal que protege al capital y desprotege dejando la responsabilidad a los individuos, nos hace aparecer un escenario, un panorama de sujetos de trabajo social que hoy día se podrían denominar como los rostros duros de la modernización. La modernización enfrentada a su dialéctica permanente genera a la vez riqueza y pobreza, integración y exclusión social, por lo tanto en ese sentido, los mecanismos de integración social no es que se hayan vuelto tremendamente incompetentes, sino que quedan atrapados en esta maquinaria que de alguna manera produce más pero que para nosotros muchas veces significa menos.

¿Cómo entender esto?, que más puede ser menos, que a pesar de los esfuerzos que hagamos en políticas sociales educacionales, por ejemplo, los resultados pueden ser menos. Del siguiente modo si comparamos América Latina en 1960 las tazas de analfabetismo con las tazas de analfabetismo que tenemos hoy, la diferencia podría 
aparecer en cifras como extremadamente favorables. Sin embargo, si relacionamos, los índices de movilidad educacional en relación con los mecanismos de trabajo, vemos que tenemos una dificultad creciente, es decir, aquella persona que en 1960, que por las campañas de alfabetismo, o educación escolar completa lograba tener un impulso educacional de alrededor de 7 u 8 años, estaba en la puerta del umbral de un tipo de mercado de trabajo; hoy, y estos son datos oficiales de la UNICEF y son importantes por los datos de la OIT, y por los datos del Banco Mundial, se necesitan alrededor de16 años de educación formal para asegurar un poco de umbral de estabilidad relativa, en términos de los mercados de trabajo. El problema, la paradoja es la siguiente: si nosotros pensamos en los jóvenes de América Latina, casi la mitad de ellos no consiguen 16 años de educación formal, por lo tanto, cómo insertarse en el mercado laboral que se ha vuelto, para nosotros, cada vez más flexible y precarizado. De allí la necesidad de dar cuenta de esta negatividad de que el Trabajo Social pudiera elaborar de forma específica, de forma particular, en las ciudades específicas y particulares, con sus problemas específicos y particulares, una cierta cartografía de la desigualdad. Tenemos todavía referencias demasiado abstractas, un poco, cambiable de lo que es la pobreza, porque se mide como si lo hubiera hecho un contador tuerto, porque se mide por los haberes y no por las deudas y una de las cosas más importantes de los últimos 20 años, como va a decir Deleusse, "el hombre contemporáneo más que un hombre alienado pasa a ser un hombre endeudado", por lo tanto, los índices de pobreza ya no se pueden calcular solamente por ausencia, por carencia de.., sino por ese frágil equilibrio entre las posibilidades de rentabilidad que entran y de alguna manera los haberes que ya están comprometidos y que hacen que, miles y miles de familias del continente latinoamericano vivan solamente para pagar las deudas contraídas de crédito de corto y mediano plazo, que son cifras, según últimas investigaciones de la OEA, hasta cinco veces el salario que esa familia tiene. Por lo tanto, en este mismo sentido los rostros duros de la modernización, no sólo se nos aparecen unidos, articulados hoy día por las formas de la indigencia o de la pobreza, nosotros tenemos hoy figuras que se gestan en los programas sociales como verdaderas figuras amenazantes jóvenes con infracción de ley, las formas duras de la organización social, los rostros fantasmagónicos del temor y del miedo, la inseguridad y la desprotección en nuestras ciudades; de alguna manera esto que funciona para lo que llamaba esa industria cultural de masas, también funciona por negatividad.

¿Qué queremos decir con esto? Que de alguna forma esos rostros, esas imágenes, nos acompañan como si fueran una fotografía, como si fuera nuestro reverso negativo, en este caso, yo disiento de ese planteamiento que nos asegura que hoy día masas enteras de la población nos resultan innecesarias, esto solo si nosotros reducimos la mirada de lo social a una mirada economicista, pero socialmente se han vuelto necesarias porque conforman nuestra identidad en forma negativa, nos permiten decir a las madres de familia, "por suerte mis hijos no son de esos, aquellos que están parados en la esquina, que son 
drogadictos, que están involucrados en las redes del tráfico", que de alguna manera nos están vendiendo seguridad o protección a cambio de un sistema de contrato, etc. Entonces en este caso, muchas veces se nos presentan naturalizadamente y aquí hay un enorme desafío para los mecanismos de integración social, es lo que a mí me gusta llamar "los mecanismos de intervención social como gramática", es decir, poner el acento en lo que la intervención social nunca puede perder de vista. La intervención social es ante todo una categoría simbólica de expresión.

Fíjense ustedes que ya en el siglo XVI cuando San Vicente de Paul consiguió audiencia después de tres años, con el rey Luis XIII, en Francia, y le dice lo siguiente: "su majestad, en las calles de París la vida de los niños vale menos que la vida de los gallos, nosotros estamos acostumbrados a ver los cadáveres de los niños flotando por el río Sena, yo le pido que parte de los dineros del tesoro real vayan para favorecer a esos niños", y él le contesta: "Abad, usted me está pidiendo algo imposible: que el tesoro de Francia se dedique a cuidar de sus hijos bastardos" "Los bastardos en alguna manera", dice el rey, "van a provocar la decadencia total de Francia si son reconocidos públicamente". "Muy simple mi señor, es cosa de cambiarles el nombre".

Así surge la primera casa de niños expósitos en Francia, porque la semantización al cambiarle a bastardo y era indudablemente no sólo una recriminación material sino moral a la idea de expósito el que está afuera, el que está desamparado, involucró que en este sentido la política francesa no se viera involucrada, protegiendo una suerte de inmoralidad producida en su territorio. Esto es lo que posteriormente hace fundar en América Latina en el siglo XIX, las casas de expósitos, que después se cambian a casas de protección de la infancia. Entonces el término de bastardos, expósitos, infantes, menores en situaciones regulares o niños vulnerados en sus derechos, tenemos una gama enorme donde la marca de la intervención social va a producir distintos tipos de estigmatización o distintas posibilidades de intervención social.

Si yo salgo de la oficina de un trabajador social, no como Teresa Matus, sino como miembro de una familia disfuncional, es una marca que me va a acompañar en muchas momentos de la vida. En este sentido tenemos que innovar en las intervenciones sociales en forma consistente, en forma sistemática y en forma compleja, ¿en qué consiste esta innovación? para hacerlo, y en este sentido a la luz de las hipótesis precedentes, otra paradoja, es que no podemos pensar ya la intervención simplemente como práctica en esa división clásica entre teoría y práctica, porque como lo acabo de demostrar, la intervención contiene una forma de ver, un régimen de la mirada que se traduce en términos de la práctica social. Por ejemplo, la forma extraordinaria como el presidente Lagos, planteaba hace una semana en Chile. Presentó un nuevo programa de derechos humanos basado en tres ejes fundamentales: la verdad, la justicia y la reparación. Decía algo que era sustantivamente innovador a la forma en que ciertos ámbitos de la política chilena asumían el tema sobre los derechos humanos que decían que "ya está bueno de hablar del pasado, tenemos que 
proyectarnos hacia el futuro". En el discurso fue clarísima la idea de que un país, una ciudad, una comunidad no logra proyectar su futuro sin considerar el ayer, es decir no hay futuro sin memoria; de allí que la memoria que nosotros podamos aportar con nuestras intervenciones sociales, memorias que ya están precedidas por aquellas generaciones del año 20 del año 30 que fundamentaron en nuestro continente las premisas de lo que es hoy el trabajo social con esa historia de nuestro propio movimiento crítico de Reconceptualización.

El punto es ¿cómo desde allí, desde nuestra historia, desde nuestra generación, que somos la generación de la post-reconceptualización, de la post-contestadura, de las revoluciones, podemos aportar en términos de la intervención social?. Lo que yo me atrevería a decir en este camino de avanzar de la negatividad, es lo que no podemos ofrecer, no podemos ofrecer menos, no podemos ofrecer sólo un panorama de reformas, no podemos ofrecer todavía hoy la homologación reductiva de la transformación social porque el viejo canon no calza con las nuevas realidades, sino en forma extraordinariamente forzada con nuestras nuevas realidades. Por lo tanto, la innovación para ser exitosa tiene que surgir, de su origen, de hacer ruina, de volver a revisar críticamente lo que encierran las formulaciones teóricas que nosotros nos planteamos en la intervención social para poder dar lugar a una visión de la integración desencantada; nosotros necesitamos de ese desencanto. Para que ese desencanto pueda fructificar. Por lo tanto necesitamos una visión desencantada y fructífera, donde ya las promesas, hacia la población de la comunidad, hacia la población juvenil, hacia los centros de organización social, no sean promesas de integración social superficiales, donde nosotros le digamos a los jóvenes que con determinados cursos de capacitación que son extraordinariamente básicos, ellos se van a poder incorporar en forma permanente y constante al mundo laboral.

Fíjense ustedes que el FOSE, que es el organismo social que se dedica a programas de intervención sociales fundamentalmente innovadores, generó un programa extraordinariamente interesante para reemplazar los programas de los sistemas de libertad condicional y el programa se llamó justamente "Hoy es mi tiempo", porque el tiempo de la integración como oportunidad de vida es lo que genera para esas personas un cambio en la lógica, en la forma de las oportunidades directas de integración social y aquí la lógica de la desconfianza, la lógica del control, se cambió por una teoría de la confianza y de alguna manera en vez de tener esa semántica que es absolutamente contradictoria, que es la de tener una libertad vigilada, que la idea de si ya es imposible de ser pensada el tener, como hoy es mi tiempo, mi tiempo de oportunidad y de rehabilitación funcionó mucho más que los sistemas de amenaza, que los sistemas de control, que los sistemas de firma, de alguna manera esto conlleva a cooperaciones en la integración social diversa. Se les entregó a las personas un capital, se les ayudó a pensar qué querían hacer con ese capital, ya sea insertarse en un medio laboral, ya sea terminar su estudio y de esa manera se fue consiguiendo una imagen social distinta la cual tenía como promesa al cabo de dos 
años, siempre y cuando sus antecedentes legales fueran menores borrarse de sus fichas, la posibilidad de partir de cero y con cuenta nueva para su vinculación a la actividad laboral. Entonces la idea de tiempo como una oportunidad, la idea simbólica de tiempo, esa idea de tiempo de la memoria del recuerdo, ese tiempo fenomenológico es el tiempo donde las personas desarrollamos la plenitud de la vida, ese es el tiempo que la intervención social no puede dejar de marcar.

Un tiempo que además requiere del proceso de rentabilidad de mediano plazo porque, un ejemplo clarísimo en el área de vivienda, los procesos de acompañamiento con las comunidades que muchas veces se ven como extraordinariamente caros por los municipios, quedan vistos como el orden del pecado porque justamente el proceso de evaluación se corta cuando el alcalde o representante del gobierno corta la cinta y les entrega la casa; ahora nadie mide o al menos hay menos medición de lo que pasa en esos barrios; algunas mediciones hechas sobre todo en Brasil, a propósito de los programas tanto en Favelas como en el presupuesto participativo demostraron que el acompañamiento comunitario, que la base social que está en un proceso comunitario con y desde los protagonistas, indudablemente ahorra un tremendo esfuerzo público a mediano plazo porque el barrio se constituye con mayor seguridad social, con mejor cuidado de los espacios públicos, con una identidad colectiva que se va construyendo entre los protagonistas e incluso con una rentabilidad del espacio habitacional que hace que la inversión no sólo se considere como una inversión sino también en el sentido económico. Yo decía que habían dos condiciones: la primera es la del tiempo, la segunda, tiene que ver directamente con entender que las formas de intervención social deben dejar de operar solamente por la demanda y debe innovar en términos de sus ofertas, ¿qué quiero decir con esto? que todavía tenemos muchas veces en las intervenciones sociales, evaluaciones demasiado planas, demasiado positivas o demasiado absolutamente negativas; todavía tenemos demasiados marcos lógicos que dividen, obstaculizadores de facilitadores, como si una cosa no pudiera hacerse contraria. Tenemos todavía demasiados NO en la intervención, la intervención muchas veces se hace para que las personas no vuelvan a delinquir, no vuelvan a consumir drogas, no vuelvan a las condiciones precarias de las cuales partieron, pero hay una escasez de modelos de expectativas, de demandas propositivas, es decir, nuevamente conectándonos con el tiempo, no solo tenemos que decirle al individuo que no consuma droga sino cuál es la propuesta social en términos de ciudadanía, que está contenido en esa propuesta de intervención social.

Y ya pasando a las condiciones más operativas, uno podría decir que tres condiciones son fundamentales. La primera, ajustes propositivos de la intervención, es decir, esto tiene que ver con todas las personas que se van involucrando en la intervención social; muchas veces nosotros en América Latina tenemos una cierta conducta doble y le pedimos confianza, innovación, participación a los usuarios, pero sin embargo, quienes trabajamos para hacer posible este programa somos evaluados nosotros mismos a nivel de las 
autoridades centrales, de las universidades, de los juzgados, de los municipios, de las gobernaciones regionales, por una lógica de evaluación extraordinariamente clásica, de control, por la idea de si estoy o no estoy todos los días en el lugar de trabajo y no en virtud espacial de los objetivos, en virtud de la productividad, en virtud de la reflexión y de la innovación que nosotros podemos proponer. Por eso, muchos de los funcionarios encargados de llevar adelante los programas sociales, más que ser medidos por sus ideas, más que ser medidos por sus aportes, por sus proyectos, son medidos por su buena salud, son medidos por si están o no están todos los días en sus lugares de trabajo; esto nos coloca en una extraordinaria desproporción, según los resultados del Banco Mundial.

El segundo, el énfasis en los mecanismos de reflexión en la intervención social. Creo que a lo largo del continente se ha abusado en forma bastante negativa de ciertas metodologías, de cierto tipo de dinámicas de grupo, de cierto tipo de formas poco reflexivas y en ese sentido creo que el énfasis hace que la reflexividad, hace que la intervención social coincida en que los propios usuarios, que las propias personas en términos de dirigir sus proyectos, puedan tener una mejor imagen, una imagen más completa, más integral, más crítica, mas reflexiva del proceso social que vivimos nosotros en su conjunto y en el cual todos estamos involucrados. Haría que de algún modo esa intervención contribuyera no solamente a un fin, especifico y particular, sino que contribuyera a potenciar mayores niveles de ciudadanía; en este sentido es vital considerar en las investigaciones un tipo de constelaciones que llevaría uno, un dispositivo como llevaría Foucault, en términos de intervención social que nos dé cuenta por lo tanto de esta cartografía, de estas dificultades como de las medidas propositivas. Que junto con los protagonistas, las personas, todos los afectados, todos los involucrados, saben encontrar mediante mecanismos de diálogo, participativos y comunicativos, las mejores formas de poder escoger contingentemente. Porque si hay algo, si hay un terreno en el cual la intervención social se mueve, es en el terreno precisamente de la contingencia.

Es decir, no en el terreno de las necesidades absolutas, sino en el terreno de tener que escoger, tener que seleccionar dentro de un panorama donde las personas siempre necesitan una cantidad de cosas, aquellas que vamos a priorizar, aquellas que vamos a seleccionar indudablemente esto significa ganancias y pérdidas, en eso estamos instalados, así es nuestra contingencia. Sin embargo, para esto el girar en la propuesta de integración social, implicaría dos condiciones finales a las cuales yo me quiero referir. La primera es considerar que la intervención es un cruce entre sujetos y fenómenos, es decir, algo que puede parecer chocante; el trabajador social no trabaja cara a cara con una persona, nunca ha trabajado cara acara con un grupo o con una comunidad. ¿Cómo, van a decir ustedes, si toda nuestra intervención nosotros la desarrollamos cara a cara con la gente?, porque, amigos míos, nadie va a ver a un trabajador social en su condición de persona natural, sino que el sujeto se nos aparece mediado, se nos aparece como portador de una categoría, como la mujer golpeada, como un presidente de sindicato , como una comunidad 
que quiere armar y mejorar su plan de desarrollo local, por lo tanto, depende de cómo yo considere, de cómo yo nombre a esa categoría. Acuérdense de bastardo, expósito, niños, menores, situación regular, cada una de aquellas denominaciones semánticas, aquellos discursos, aquellas retóricas van a ser traspasadas y van a crear obstáculos o posibilidades en términos de intervención o de la práctica social. En este sentido, como ya va a decir largamente Foucault, el discurso contiene posibilidades de vida y posibilidades de muerte, en esto, la semántica se juega en forma muy importante en los procesos de integración social.

Un ejemplo, la idea de exclusión social. El sentido común hace pensar que la exclusión se refiere a aquellas personas que están fuera de.... Las formas de exclusión social nos muestran no los que están afuera, nos muestran los que están en el centro, en la vorágine, sufriendo los mayores golpes, los mayores impactos de la dialéctica de la modernización, en este sentido nosotros hemos sido claramente impactados por esos sujetos, esos sujetos no están afuera, esos sujetos están al centro por que si hay alguien que van a despedir, va a ser a ellos, si hay alguien a quien van a recortar salarios, va a ser a ellos, si hay alguien a quien van a quitar beneficios sociales, va a ser a ellos, si hay alguien a que va a tener mayores miedos y mayor inseguridad, van a ser ellos, entonces, es extraordinariamente opaco, oscurecedor; es como ver a personas que están siendo golpeadas en el centro de un tren y decir que esas personas están excluidas. La exclusión es de los beneficios, pero incluye que aún así ellos comparten la lógica de aspiración de los propios programas del proceso de movilización, en este sentido no solo tenemos que pensar tanto en que la exclusión no está afuera sino adentro, sino que además la exclusión es algo que no se puede dejar de pensar sin su parte contraria, la integración, es decir, como ya nos recuerda Hegel, la idea de estar construyendo una identidad se hace a la vez por la integración y por la exclusión.

Si yo estoy hoy conversando con ustedes sobre estos temas, a ustedes no solo les queda claro que yo soy una interesada en lo que nosotros discutimos, sino que también que no soy físico, que no soy químico, no soy atleta. En este sentido, las forma de identificarse, las formas de integrarse contienen no solo posibilidades en términos de ser pensada como procesos integrativos, sino que a la vez yo me integro a partir de lo que me excluyo.

Y por último, y este es el punto con el cual yo quiero concluir, ¿Para qué toda esta innovación? ¿Para qué preocuparse en términos de poder cambiar el rostro a la intervención social? Porque nosotros tenemos un encargo, cuando se genera ya en el origen de nuestro oficio, está la idea de que ya esa transformación social y esa transformación social que durante los siglos se le ha dado diversos nombres, se ha bautizado de diversa manera, nosotros hoy no podemos dejar de responderles. Es decir la interpelación ética a la convivencia pública no puede ser restringida a los códigos de ética no puede ser restringida a lo que sucede entre trabajador social y cliente porque 
además por la pura semántica el secreto profesional guarda un silencio y nosotros no queremos tener una ética para el silencio. Queremos hacer de la ética una luz, pero ¿cómo podemos hacer eso?, yo diría por lo menos que cumpliendo tres condiciones: la primera, haciendo que la ética se incluya en el horizonte de las operaciones instrumentales de la intervención y quiere decir esto que tenemos un panorama extraordinariamente abierto, una cartografía ética contemporánea que va desde el liberalismo de Rawls, de Rousseau, al comunitarismo de Marx, a la perspectiva de un socialismo dialógico de Habermas. La pregunta a los trabajadores sociales es, ¿cuáles son esos modelos éticos que vamos a usar en forma procedimental en la intervención?. Porque dependiendo de lo que pienso así se va a considerar la forma en que se negocia, la forma en que se llega al diálogo, la forma en que se operacionaliza, la forma en que se lleva a cabo la intervención. Si esto no se piensa tenemos un instrumento vacío donde la ética es solo es el discurso que está por arriba, pero que no traspasa todos los mecanismos operacionales y los procesos de integración social.

Y lo más importante, y con esto ya quisiera terminar, nos olvidamos que la intervención contiene dos niveles de interpelación ética sustantiva; la primera, que la intervención social debe aportar a la construcción de nuevas subjetividades, es decir, aportar a la construcción de identidades más reflexivas y más flexibles, porque sin sujetos que construyan una identidad más reflexiva y más flexible, difícilmente tendremos eso que Kant llamó, el paso de la minoridad a la mayoridad, es decir, vamos a tener personas pero no vamos a tener sujetos, vamos a tener personas pero no vamos a tener ciudadanos.

La idea de ciudadanía hoy no puede quedar reducida solamente a la idea de consumo o solamente o a la idea de una simple acción o pertenencia.

Y por último, no solo la intervención social contribuye a la construcción de estas subjetividades, sino que la integración social debe contribuir, debe aportar a mecanismos serios, reflexivos, a la formación de seres tan reflexivos que saben enfrentar, que saben dejarse interpretar por las contradicciones, para construir mecanismos de transformación social. La transformación social no puede ser palabra nombrada con nostalgia, la transformación social debe ser un proyecto del presente, un anhelo de futuro en el que se engloban las realidades más duras y difíciles de nuestro continente, en este sentido la transformación social contiene en este núcleo simbólico, en estas innovaciones de un mundo sin integración, en esta ética de la intervención, algunos desafíos centrales para el Trabajo Social para América Latina, que pensando en ese horizonte transformador, nosotros renovemos la intervención social contribuyendo a gestar un ámbito público, retomando a Hana Arendt, en su pleno resplandor. 